\title{
Serum Cotinine Levels and Prehypertension in Never Smokers
}

\author{
Omayma Alshaarawy, ${ }^{1}$ Jie Xiao, ${ }^{1}$ Michael E. Andrew, ${ }^{2}$ Cecil Burchfiel, ${ }^{2}$ and Anoop Shankar' \\ ${ }^{1}$ Department of Epidemiology, West Virginia University School of Public Health, 1 Medical Center Drive, P.O. Box 9190, \\ Morgantown, WV 26506, USA \\ ${ }^{2}$ Biostatistics and Epidemiology Branch, Health Effects Laboratory Division, National Institute for Occupational Safety and Health, \\ Centers for Disease Control and Prevention, Morgantown, WV 26505, USA
}

Correspondence should be addressed to Anoop Shankar; anoopshankar@yahoo.com

Received 31 October 2012; Accepted 9 January 2013

Academic Editor: B. Waeber

Copyright ( $) 2013$ Omayma Alshaarawy et al. This is an open access article distributed under the Creative Commons Attribution License, which permits unrestricted use, distribution, and reproduction in any medium, provided the original work is properly cited.

\begin{abstract}
Background. Few studies have shown that self-reported secondhand smoke exposure in never smokers is associated with high blood pressure. However, there are no studies investigating the relationship between secondhand smoke exposure, measured objectively by serum cotinine levels, and high blood pressure in never smokers. Methods. We examined never smokers $(n=2027)$ from the National Health and Nutrition Examination Survey 2005-2008. Our exposure of interest was the secondhand smoke exposure estimated by serum cotinine level and our outcome was prehypertension $(n=734)$, defined as a systolic blood pressure of $120-$ $139 \mathrm{mmHg}$ or diastolic blood pressure of $80-89 \mathrm{mmHg}$. Results. We found that, in never smokers, serum cotinine levels were positively associated with prehypertension. Compared to those with cotinine levels in the lowest quartile $(\leq 0.024 \mathrm{ng} / \mathrm{mL})$, the multivariable odds ratio (95\% confidence interval) of prehypertension among those with cotinine levels in the highest quartile $(\geq 0.224 \mathrm{ng} / \mathrm{mL})$ was $1.45(1.00,2.11) ; P$ trend $=0.0451$. In subsequent subgroup analyses, the positive association was found to be stronger among men, non-Whites, and non-obese subjects. Conclusion. Higher secondhand smoke exposure measured objectively by serum cotinine levels was found to be associated with prehypertension in certain subgroups of a representative sample of the US population.
\end{abstract}

\section{Introduction}

Smoking is now recognized to be a major preventable risk factor for numerous outcomes, including cardiovascular diseases (CVD), and mortality [1-4]. Hypertension is a major public health problem affecting approximately $31.3 \%$ of US adults [5] and a well-recognized risk factor for CVD endstage renal disease, and increased mortality. Several studies have reported an association between active smoking and hypertension among smokers $[4,6,7]$. However, it is not clear if, among nonsmokers, exposure to secondhand smoke (SHS) is a risk for increased blood pressure. There are only a few studies investigating the relationship between SHS and increased blood pressure in nonsmokers and all of these studies used self-reported exposure to SHS which is prone to misclassification [8-11].

Prehypertension, defined as systolic blood pressure (BP) ranging from $120-139 \mathrm{mmHg}$ or diastolic $\mathrm{BP}$ ranging from $80-89 \mathrm{mmHg}$, is a preclinical stage in the high BP continuum, where subjects are at increased risk of developing hypertension in the near future [12]. From a prevention perspective, it is an important stage as an emerging body of the literature suggests that interventions at the prehypertension stage can prevent or delay the progression into established hypertension [13-18]. In this context, we examined the association between SHS exposure measured objectively by serum cotinine level and prehypertension among never smokers in a nationally representative sample of US adults after adjusting for age, sex, ethnicity, BMI, and other potential confounders.

\section{Methods}

The data for this study are derived from the National Health and Nutrition Examination Survey 2005-2008. Detailed description of NHANES study design and methods is available elsewhere $[19,20]$. The NHANES included a stratified multistage probability sample representative of the civilian 
noninstitutionalized US population. Selection was based on counties, blocks, households, and individuals within households and included oversampling of non-Hispanic Blacks and Mexican Americans in order to provide stable estimates of these groups.

Out of 20497 participants in NHANES 2005-2008, there were 10914 who were $>20$ years of age. We further excluded participants who were pregnant $(n=393)$, had prevalent cardiovascular disease $(n=1275)$, were former and current smokers $(n=4982)$, had hypertension defined as self-reported current BP-reducing medication use, and/or had systolic $\mathrm{BP} \geq 140 \mathrm{mmHg}$ and/or diastolic BP $\geq 90 \mathrm{mmHg}(n=1036)$, had missing or below the limit of detection $(0.011 \mathrm{ng} / \mathrm{mL})$ of serum cotinine level $(n=999)$, and those with missing information on systolic BP, diastolic BP, or other covariates $(n=202)$ included in the multivariable model. This resulted in 2027 participants who were included in the final analysis.

\subsection{Main Outcome of Interest}

2.1.1. Prehypertension. Seated systolic and diastolic BPs were measured using a mercury sphygmomanometer according to the American Heart Association and JNC7 recommendations [21]. Up to 3 measurements were averaged for systolic and diastolic pressures. The outcome of interest in the current study was the presence of prehypertension, defined as systolic BP $120-139 \mathrm{mmHg}$ systolic or diastolic BP $80-89 \mathrm{mmHg}$ based on JNC7 criteria [22].

\subsection{Exposure Measurements. Serum specimens were pro-} cessed, stored, and shipped to the Division of Laboratory Sciences, National Center for Environmental Health, and Centers for Disease Control and Prevention for analysis. Detailed specimen collection and processing instructions were discussed in the NHANES Laboratory/Medical Technologists Procedures Manual (LPM). Serum cotinine was measured by isotope dilution high-performance liquid chromatography atmospheric pressure chemical ionization tandem mass spectrometry (ID HPLC-APCI MS/MS). Briefly, the serum sample was spiked with methyl-D3 cotinine as an internal standard, and after an equilibration period, the sample was applied to a basified solid-phase extraction column. Cotinine was extracted off the column with methylene chloride, the organic extract was concentrated, and the residue was injected onto a short C18 HPLC column. The eluant from these injections was monitored by APCI-MS/MS, and the $m / z$ 80 daughter ion from the $\mathrm{m} / z 177$ quasi-molecular ion was quantitated, along with additional ions for the internal standard, external standard, and for confirmation. Cotinine concentrations were derived from the ratio of native to labeled cotinine in the sample, by comparisons to a standard curve. Detailed description of serum cotinine measurement in NHANES is available online $[20,23]$. Serum total cholesterol was measured enzymatically. Glycosylated hemoglobin measurements were performed on the Tosoh 2.2 Analyzer (Tosoh Medics, Inc., 347 Oyster Pt. Blvd., Suite 201, So. San Francisco, CA 94080, USA) in NHANES 2005-2006 and on the Automated HPLC System Glycohemoglobin Analyzer
(Tosoh Medics, Inc., 347 Oyster Pt. Blvd., Suite 201, So.San Francisco, CA 94080, USA) in NHANES 2007-2008 at the University of Minnesota, Minneapolis, Minnesota, USA [20, 23].

Information on age, gender, race/ethnicity, alcohol intake (g/day), income, level of education, female hormone use, and cigarette smoking were obtained from a standardized questionnaire during a home interview. Income-poverty ratio was used as a measure of socioeconomic status. The Department of Health and Human Services' poverty guidelines were used to calculate this index. Poverty status was categorized into living below the federal poverty level (less than 1.00) and living at or above the federal poverty level (1.00 or more). Educational attainment was categorized into less than high school graduate, high school graduate, and more than high school graduate. Females who ever used estrogen or progesterone hormones, other than for birth control or fertility, were categorized into used/never used. Smoking status was categorized into never smokers (smoked $<100$ cigarettes during their lifetime), former smokers (smoked $\geq 100$ cigarettes lifetime and currently not smoking), and current smokers (smoked $\geq 100$ cigarettes lifetime and currently smoking) $[19,20]$. Alcohol consumption was categorized into never drinking, former drinking, moderate (less than 3 drinks/day) and heavy drinker (3 or more drinks per day). Information on anthropometric, physical, and laboratory components were obtained during the medical examination center (MEC) examination. Body mass index (BMI) was calculated as weight in kilograms divided by height in meters squared.

2.3. Statistical Analysis. Serum cotinine levels were analyzed both as a continuous as well as a categorical variable. For analysis as a continuous variable, serum cotinine levels were log-transformed as a result of their skewed distribution. To examine the proportion of variance explained by including passive smoking, we calculated the modified $R^{2}$ values [24]. We categorized serum cotinine level into quartiles. We ran logistic regression models to calculate the odds ratio ((OR) and $95 \%$ confidence interval (CI)) of prehypertension for each higher serum cotinine quartile by using the lowest category as the referent. We ran two nested models, the age, sex adjusted model and the multivariable-adjusted model, additionally adjusting for ethnicity (non-Hispanic White, non-Hispanic Black, Mexican Americans and others), alcohol drinking (never drinker, former drinker, 1 or 2 drinks/day, $\geq 3$ drinks/day), education (less than high school, high school, more than high school), poverty (living below the federal poverty level, living at or above the federal poverty level), use of female hormones (ever, never), BMI (normal weight, overweight, obese), glycosylated hemoglobin (\%), and total cholesterol $(\mathrm{mg} / \mathrm{dL})$. To further ensure that the association is parallel for subgroups and rule out effect modification, we performed subgroup analyses by gender, race/ethnicity, and BMI categories. Trends in the OR of prehypertension across increasing serum cotinine levels were determined by modeling serum cotinine categories as an ordinal variable. Sample weights that account for the unequal probabilities of selection, oversampling, and nonresponse in the NHANES 
TABLE 1: Baseline characteristics of the study population.

\begin{tabular}{|c|c|}
\hline Characteristics & $\begin{array}{c}\text { Mean values } \pm \text { standard error (SE) } \\
\text { or } \\
\text { Sample size (weighted percentages) }\end{array}$ \\
\hline Total sample size & 2027 \\
\hline Women (\%) & $1109(53.8 \%)$ \\
\hline Age (years) & $39.1 \pm 0.5$ \\
\hline \multicolumn{2}{|l|}{ Race/ethnicity (\%) } \\
\hline Non-Hispanic Whites & $773(61.9 \%)$ \\
\hline Non-Hispanic Blacks & $452(12.6 \%)$ \\
\hline Mexican Americans & $484(11.4 \%)$ \\
\hline Others & $318(14.1 \%)$ \\
\hline \multicolumn{2}{|l|}{ Education categories (\%) } \\
\hline Below high school & $496(15.3)$ \\
\hline High school & $467(22.0)$ \\
\hline Above high school & $1064(62.7)$ \\
\hline \multicolumn{2}{|l|}{ Alcohol intake (\%) } \\
\hline Never drinker & $358(14.9 \%)$ \\
\hline Former drinker & $376(16.4 \%)$ \\
\hline $\begin{array}{l}\text { Moderate drinker ( } 1 \text { or } 2 \\
\text { drink/day) }\end{array}$ & $815(46.0 \%)$ \\
\hline $\begin{array}{l}\text { Heavy drinker ( } \geq 3 \\
\text { drinks/day) }\end{array}$ & $478(22.7 \%)$ \\
\hline \multicolumn{2}{|l|}{ Body mass index (\%) } \\
\hline $\begin{array}{l}\text { Normal weight } \\
\left(<25.0 \mathrm{~kg} / \mathrm{m}^{2}\right)\end{array}$ & $647(35.2 \%)$ \\
\hline $\begin{array}{l}\text { Overweight } \\
\left(25.0-29.9 \mathrm{~kg} / \mathrm{m}^{2}\right)\end{array}$ & $709(34.6 \%)$ \\
\hline Obese $\left(\geq 30.0 \mathrm{~kg} / \mathrm{m}^{2}\right)$ & $671(30.2 \%)$ \\
\hline $\begin{array}{l}\text { Serum cotinine }(\mathrm{ng} / \mathrm{mL}) \\
\text { (geometric mean) }\end{array}$ & $0.1 \pm 0.01$ \\
\hline Glycosylated hemoglobin (\%) & $5.3 \pm 0.02$ \\
\hline Total cholesterol (mg/dL) & $195.9 \pm 1.2$ \\
\hline $\begin{array}{l}\text { Systolic blood pressure, } \\
\mathrm{mmHg}\end{array}$ & $114.4 \pm 0.3$ \\
\hline $\begin{array}{l}\text { Diastolic blood pressure, } \\
\mathrm{mmHg}\end{array}$ & $69.1 \pm 0.3$ \\
\hline Below poverty level (\%) & $379(12.2)$ \\
\hline Prehypertension (\%) & $734(35.9)$ \\
\hline
\end{tabular}

survey were applied for all analyses. Analyses were conducted using SAS (version 9.3, SAS Institute, Cary, NC, USA) software. Standard errors were estimated using the Taylor series linearization method.

\section{Results}

Table 1 presents the baseline characteristics of the study population, all of whom were never smokers. Among 2027 participants included in the study, approximately $54 \%$ were women and $62 \%$ were non-Hispanic White. Normal weight, overweight, and obese BMI categories were equally distributed. Prehypertension was present in $35.9 \%$ of the study population. The geometric mean of serum cotinine level was $0.1 \pm 0.01 \mathrm{ng} / \mathrm{mL}$. Compared with subjects who were included in the final study sample, those who were excluded owing to missing data were significantly more likely to be female and non-Hispanic White, but were similar with respect to other sociodemographic characteristics listed in Table 1.

Table 2 presents the association between serum cotinine levels and prehypertension. Serum cotinine levels were found to be positively associated with prehypertension in the age-, sex-adjusted model. Tests for linear trends for this association in the age, sex adjusted model as well as the multivariableadjusted model were statistically significant. We performed an analysis where we calculated the modified $R^{2}$ from the multivariable logistic regression model. The $R^{2}$ in the multivariable model was 0.15 suggesting that $15 \%$ of the variance in the multivariable model for prehypertension was explained by serum cotinine. We also performed a supplementary analysis where we used serum cotinine $(\mathrm{ng} / \mathrm{mL})$ as a continuous variable. The multivariable odds ratio [95\% C.I] of prehypertension was 1.039 [0.994, 1.085].

Next, to primarily examine confounding, we performed subgroup analyses by gender, race/ethnicity and BMI categories in Tables 3-5. In the subgroup analysis by gender (Table 3), the observed positive association between higher serum cotinine levels and prehypertension was mainly evident in men. In the subgroup analysis by race/ethnicity (Table 4), we observed that the positive association between higher serum cotinine levels and prehypertension was mainly present in non-whites, but not in whites. Finally, in the subgroup analysis by BMI (Table 5), we observed that the positive association between higher serum cotinine levels and prehypertension was mainly present in the nonobese group (BMI $<30 \mathrm{~kg} / \mathrm{m}^{2}$ ), but not in obese subjects (BMI $\geq 30 \mathrm{~kg} / \mathrm{m}^{2}$ ). $P$ interaction values for cross-product terms between cotinine levels X stratifying variables were all $>0.2$ except for gender (0.03).

We performed a supplementary analysis (shown in Table 6) where we confined the analysis to self-reported never smokers with serum cotinine levels $<10 \mathrm{ng} / \mathrm{mL}$; the results in this subgroup of low serum cotinine subjects were similar to our main findings in Table 2.

\section{Discussion}

Among never smokers in the US general population who were free of hypertension, we initially found that higher levels of serum cotinine, an objective marker of SHS exposure, were positively associated with prehypertension independent of confounders. However, in subsequent subgroup analyses, the positive association was present only among men, but not women; among non-Whites, but not Whites; and among nonobese, but not obese subjects.

Prehypertension is a preclinical stage where subjects are at increased risk of developing hypertension in the near future. Several previous studies have reported a positive association between smoking and hypertension [6, 7, 25-27]. An unintended consequence of smoking is exposure to SHS in nonsmokers. There are few studies investigating 
TABLE 2: Association between serum cotinine levels and prehypertension.

\begin{tabular}{lcccc}
\hline Cotinine quartiles & No. at risk & Cases & $\begin{array}{c}\text { Age-, sex-adjusted odds ratio } \\
(95 \% \text { confidence interval })\end{array}$ & $\begin{array}{c}\text { Multivariable-adjusted odds ratio } \\
\text { (95\% confidence interval) }^{*}\end{array}$ \\
\hline Quartile 1 $(\leq 0.024 \mathrm{ng} / \mathrm{mL})$ & 488 & 165 & 1 (referent) & 1 (referent) \\
Quartile 2 $(0.025-0.054 \mathrm{ng} / \mathrm{mL})$ & 524 & 188 & $1.19(0.89,1.60)$ & $1.19(0.90,1.58)$ \\
Quartile 3 $(0.055-0.223 \mathrm{ng} / \mathrm{mL})$ & 508 & 185 & $1.44(1.02,2.02)$ & $1.38(0.97,1.96)$ \\
Quartile 4 $(\geq 0.224 \mathrm{ng} / \mathrm{mL})$ & 507 & 196 & $1.53(1.07,2.19)$ & $1.45(1.00,2.11)$ \\
$P$ trend & & & 0.0142 & 0.0451 \\
\hline
\end{tabular}

*Adjusted for age (years), sex (men, women), ethnicity (non-Hispanic White, non-Hispanic Black, Mexican Americans, others), education categories (<high school, high school, >high school), drinking (never drinker, former drinker, 1 or 2 drink/day, $\geq 3$ drinks/day), BMI (normal weight, overweight, obese), glycohemoglobin (\%), total cholesterol (mg/dL), below poverty level (\%), and hormone use (ever, never).

TABLE 3: Association between serum cotinine levels and prehypertension, by gender.

\begin{tabular}{|c|c|c|c|c|}
\hline Serum cotinine quartiles & No. at risk & Cases & $\begin{array}{l}\text { Age-adjusted odds ratio } \\
\text { (95\% CI) }\end{array}$ & $\begin{array}{l}\text { Multivariable-adjusted odds ratio } \\
(95 \% \mathrm{CI})^{*}\end{array}$ \\
\hline \multicolumn{5}{|l|}{ Men } \\
\hline Quartile $1(\leq 0.024 \mathrm{ng} / \mathrm{mL})$ & 192 & 74 & 1 (referent) & 1 (referent) \\
\hline Quartile $2(0.025-0.054 \mathrm{ng} / \mathrm{mL})$ & 228 & 108 & $1.59(1.00,2.54)$ & $1.62(1.00,2.62)$ \\
\hline Quartile $3(0.055-0.223 \mathrm{ng} / \mathrm{mL})$ & 225 & 105 & $1.85(1.06,3.22)$ & $1.82(1.02,3.23)$ \\
\hline Quartile $4(\geq 0.224 \mathrm{ng} / \mathrm{mL})$ & 273 & 136 & $1.87(1.15,3.04)$ & $1.80(1.09,2.98)$ \\
\hline$P$ trend & & & 0.0209 & 0.0406 \\
\hline \multicolumn{5}{|l|}{ Women } \\
\hline Quartile $1(\leq 0.024 \mathrm{ng} / \mathrm{mL})$ & 296 & 91 & 1 (referent) & 1 (referent) \\
\hline Quartile $2(0.025-0.054 \mathrm{ng} / \mathrm{mL})$ & 296 & 80 & $0.89(0.58,1.37)$ & $0.86(0.57,1.29)$ \\
\hline Quartile $3(0.055-0.223 \mathrm{ng} / \mathrm{mL})$ & 283 & 80 & $1.23(0.80,1.92)$ & $1.14(0.71,1.81)$ \\
\hline Quartile $4(\geq 0.224 \mathrm{ng} / \mathrm{mL})$ & 234 & 60 & $1.17(0.75,1.83)$ & $1.02(0.64,1.63)$ \\
\hline$P$ trend & & & 0.2413 & 0.6185 \\
\hline
\end{tabular}

${ }^{*}$ Adjusted for age (years), ethnicity (non-Hispanic White, non-Hispanic Black, Mexican Americans, others), education categories (<high school, high school, $>$ high school), drinking (never drinker, former drinker, 1 or 2 drink/day, $\geq 3$ drinks/day), BMI (normal weight, overweight, obese), glycohemoglobin (\%), total cholesterol (mg/dL), below poverty level (\%), and hormone use (ever, never).

$P$ interaction of cotinine quartiles and gender $=0.0303$.

the relationship between SHS exposure and prehypertension among never smokers. A cross-sectional study involving clinically normotensive passive smokers found that self-reported passive smoking was associated with increased levels of BP in a dose-related manner [28]. In another study of 30 healthy nonsmoking women, systolic and diastolic BP were found to be acutely elevated following the exposure to passive smoking [9]. However, a limitation to these studies is that SHS exposure was assessed entirely on the basis of self-report without potential benefits of more objective measures, which in turn may have resulted in exposure misclassification.

In the current study, serum cotinine level was used to measure the level of exposure to SHS among never smokers. Cotinine is the principal metabolite of nicotine and has a 15-40 hr halflife [29]. Serum cotinine is considered a more precise measure of exposure to cigarette smoking when compared to self-reported smoking status $[30,31]$ and is considered an accurate biomarker of SHS exposure [32].

The exact mechanism underlying the observed association between SHS and prehypertension in never smokers remains unknown. A vasoconstriction mediated by nicotine is initially responsible for acute but transient increase in the systolic BP [33]. This phase is followed by a decrease in BP as a consequence of nicotine depressant effects [34]. In the long run, it has been suggested that carbon monoxide acts directly on the arterial wall potentially causing endothelial dysfunction [35-38] and structurally irreversible alterations such as arterial stiffness [11]. These changes potentially lead to a state of chronically elevated $\mathrm{BP}$ and prehypertension $[10,34]$.

In the current study, we performed subgroup analysis by gender, race/ethnicity, and BMI categories with the intent to examine confounding, a practice consistent with traditional methods of epidemiologic analysis. However, in the subgroup analysis by gender, post hoc, the positive association between serum cotinine and prehypertension was found to be present only in men, but not in women, suggesting possible gender differences. It is possible that hormonal differences in the way in which men and women metabolize nicotine may explain this observation. The main pathway of nicotine metabolism is, by oxidation, mediated by cytochrome P450 (CYP) and aldehyde oxidase enzymes [39]. It has been shown that women have increased lung expression of CYP enzymes compared with men which is related to estrogen $[40,41]$. 
TABle 4: Association between serum cotinine levels and prehypertension by ethnicity.

\begin{tabular}{|c|c|c|c|c|}
\hline Serum cotinine quartiles & No. at risk & Cases & $\begin{array}{l}\text { Age-, sex-adjusted odds ratio } \\
(95 \% \mathrm{CI})\end{array}$ & $\begin{array}{l}\text { Multivariable-adjusted odds ratio } \\
(95 \% \mathrm{CI})^{*}\end{array}$ \\
\hline \multicolumn{5}{|l|}{ Whites } \\
\hline Quartile $1(\leq 0.024$ ng/mL $)$ & 191 & 67 & 1 (referent) & 1 (referent) \\
\hline Quartile $2(0.025-0.054 \mathrm{ng} / \mathrm{mL})$ & 205 & 78 & $1.16(0.76,1.78)$ & $1.17(0.76,1.81)$ \\
\hline Quartile $3(0.055-0.223 \mathrm{ng} / \mathrm{mL})$ & 195 & 87 & $1.62(1.03,2.54)$ & $1.49(0.94,2.37)$ \\
\hline Quartile $4(\geq 0.224 \mathrm{ng} / \mathrm{mL})$ & 182 & 73 & $1.38(0.80,2.37)$ & $1.31(0.75,2.28)$ \\
\hline$P$-trend & & & 0.1267 & 0.2190 \\
\hline \multicolumn{5}{|l|}{ Non-Whites } \\
\hline Quartile $1(\leq 0.024 \mathrm{ng} / \mathrm{mL})$ & 297 & 98 & 1 (referent) & 1 (referent) \\
\hline Quartile $2(0.025-0.054 \mathrm{ng} / \mathrm{mL})$ & 319 & 110 & $1.21(0.82,1.78)$ & $1.22(0.85,1.75)$ \\
\hline Quartile $3(0.055-0.223 \mathrm{ng} / \mathrm{mL})$ & 313 & 98 & $1.15(0.83,1.61)$ & $1.12(0.79,1.59)$ \\
\hline Quartile $4(\geq 0.224 \mathrm{ng} / \mathrm{mL})$ & 325 & 123 & $1.81(1.27,2.60)$ & $1.76(1.21,2.56)$ \\
\hline$P$ trend & & & 0.0043 & 0.0095 \\
\hline
\end{tabular}

*Adjusted for age (years), sex (men, women), education categories (<high school, high school, $>$ high school), drinking (never drinker, former drinker, 1 or 2 drink/day, $\geq 3$ drinks/day), BMI (normal weight, overweight, obese), glycohemoglobin (\%), total cholesterol (mg/dL), below poverty level (\%), and hormone use (ever, never).

$P$ interaction of cotinine quartiles and Whites $=0.5509$.

TABLE 5: Association between serum cotinine levels and prehypertension by body mass index.

\begin{tabular}{|c|c|c|c|c|}
\hline Serum cotinine quartiles & No. at risk & Cases & $\begin{array}{l}\text { Age-, sex-adjusted odds ratio } \\
\text { (95\% CI) }\end{array}$ & $\begin{array}{l}\text { Multivariable-adjusted odds ratio } \\
\qquad(95 \% \mathrm{CI})^{*}\end{array}$ \\
\hline \multicolumn{5}{|l|}{$\mathrm{BMI}<30 \mathrm{~kg} / \mathrm{m}^{2}$} \\
\hline Quartile $1(\leq 0.024 \mathrm{ng} / \mathrm{mL})$ & 350 & 105 & 1 (referent) & 1 (referent) \\
\hline Quartile $2(0.025-0.054 \mathrm{ng} / \mathrm{mL})$ & 355 & 120 & $1.37(0.98,1.90)$ & $1.38(1.01,1.89)$ \\
\hline Quartile $3(0.055-0.223 \mathrm{ng} / \mathrm{mL})$ & 326 & 106 & $1.79(1.14,2.81)$ & $1.79(1.13,2.83)$ \\
\hline Quartile $4(\geq 0.224 \mathrm{ng} / \mathrm{mL})$ & 325 & 114 & $1.65(1.07,2.54)$ & $1.66(1.08,2.55)$ \\
\hline$P$ trend & & & 0.0163 & 0.0167 \\
\hline \multicolumn{5}{|l|}{$\mathrm{BMI} \geq 30 \mathrm{~kg} / \mathrm{m}^{2}$} \\
\hline Quartile $1(\leq 0.024 \mathrm{ng} / \mathrm{mL})$ & 138 & 60 & 1 (Referent) & 1 (Referent) \\
\hline Quartile $2(0.025-0.054 \mathrm{ng} / \mathrm{mL})$ & 169 & 68 & $0.85(0.56,1.29)$ & $0.86(0.57,1.30)$ \\
\hline Quartile $3(0.055-0.223 \mathrm{ng} / \mathrm{mL})$ & 182 & 79 & $0.83(0.48,1.43)$ & $0.84(0.48,1.47)$ \\
\hline Quartile $4(\geq 0.224 \mathrm{ng} / \mathrm{mL})$ & 182 & 82 & $1.07(0.57,2.00)$ & $1.05(0.53,2.10)$ \\
\hline$P$ trend & & & 0.8176 & 0.8858 \\
\hline
\end{tabular}

${ }^{*}$ Adjusted for age (years), sex (men, women), ethnicity (non-Hispanic white, non-Hispanic black, Mexican Americans, others), education categories (<high school, high school, > high school), drinking (never drinker, former drinker, lor 2 drink/day, $\geq 3$ drinks/day), glycohemoglobin (\%), total cholesterol (mg/dL), below poverty level (\%), and hormone use (ever, never).

$P$-interaction of cotinine quartiles and obese $=0.3751$.

Consequently, accelerated breakdown of nicotine in the lungs may reduce circulating cotinine concentrations over time [42]. In addition, clearance of nicotine and cotinine was reported to be significantly higher in women than in men, especially in women taking oral contraceptives, indicating again that female hormones might play a key role in cotinine metabolism [39]. The underlying mechanism suggested for the effect of cotinine on blood pressure is through endothelial dysfunction and arterial stiffness, and, subsequently, higher levels of cotinine in the circulation may be related to higher endothelial dysfunction and eventually the development of prehypertension. Another suggested explanation is that differences in body fat percentage may contribute to such gender differences [43]. Women are known to have higher percentages of body fat [44-47]. Persons with relatively higher levels of body fat are likely to exhibit relatively lower cotinine activity in serum because of possible absorption of cotinine by fatty tissue [48]. This second explanatory hypothesis is also consistent with the current study's findings of no association between serum cotinine levels and prehypertension in the higher BMI group (BMI $\geq 30 \mathrm{~kg} / \mathrm{m}^{2}$ ).

Even though the magnitude of odds ratios showed substantial differences by gender and BMI categories, the $95 \%$ confidence intervals were found to be overlapping. Therefore, it is possible that the differences we are observing are due to random variability and not true causal differences. Larger 
TABLE 6: Association between serum cotinine levels and prehypertension among those with serum cotinine $<10 \mathrm{ng} / \mathrm{mL}$.

\begin{tabular}{lccc}
\hline Serum cotinine quartiles & No. at risk & Prehypertension cases & Multivariable-adjusted odds ratio (95\% confidence interval) $^{*}$ \\
\hline Quartile $1(\leq 0.024 \mathrm{ng} / \mathrm{mL})$ & 488 & 165 & 1 (referent) \\
Quartile 2 $(0.025-0.054 \mathrm{ng} / \mathrm{mL})$ & 524 & 188 & $1.21(0.91,1.60)$ \\
Quartile $3(0.055-0.223 \mathrm{ng} / \mathrm{mL})$ & 508 & 185 & $1.38(0.97,1.96)$ \\
Quartile $4(\geq 0.224 \mathrm{ng} / \mathrm{mL})$ & 370 & 140 & $1.49(1.06,2.09)$ \\
$P$ trend & & & 0.0208 \\
\hline
\end{tabular}

*Adjusted for age (years), sex (men, women), ethnicity (non-Hispanic White, non-Hispanic Black, Mexican Americans, others), education categories (<high school, high school, >high school), drinking (never drinker, former drinker, 1 or 2 drink/day, $\geq 3$ drinks/day), BMI (normal weight, overweight, obese), glycohemoglobin (\%), total cholesterol (mg/dL), below poverty level (\%), and hormone use (ever, never).

studies are needed to confirm if these observed differences in our study are statistically significant.

In a similar pattern, in the subgroup analysis by race/ ethnicity, there was a significant positive association between serum cotinine levels and prehypertension in non-Whites, but not in Whites. Similar racial/ethnic differences were previously reported in the literature related to cotinine exposure levels. For example, Black smokers had higher cotinine levels than whites and Mexican Americans [49-51] possibly due to differences in brands used, inhalation pattern or ethnic differences in cotinine metabolism [50,51]. It is also possible that there are differences in body fat percentage by race/ethnicity. For example, recent studies have shown that Whites have the highest body fat percentage for a given BMI [52].

In the current study, we were interested in the association between secondhand smoke exposure and prehypertension in never smokers. Although we included only participants who reported to be never smokers, some of these subjects had high serum cotinine levels, raising the possibility of misclassification bias with self-reported never smoking status. To address this concern, we performed a supplementary analysis shown in Table 6, limiting our analysis only to participants with serum cotinine $<10 \mathrm{ng} / \mathrm{mL}$. As expected, the results in this subgroup of low serum cotinine subjects were similar to our main findings, suggesting that misclassification due to self-reported smoking is not likely to bias our results.

This study has numerous strengths. Ours is the first study to date investigating the relationship between nicotine exposure measured objectively by serum cotinine level and prehypertension in never smokers. We believe that our use of serum cotinine will minimize the potential for misclassification bias. Moreover, the large national sample of racially and ethnically diverse US adults and the ability to adjust for numerous potential confounders add to the strengths of the study. The cross-sectional nature of NHANES represents the main limitation of the study as it does not allow us to draw conclusions regarding the causal role of nicotine exposure in prehypertension.

In summary, this study provides evidence that SHS exposure measured by serum cotinine level in never smokers is associated with the prehypertension among adults free from hypertension in the general US population. In subgroup analyses, we also found that this association was evident in men, non-Whites, and nonobese subjects. If confirmed in prospective studies, our results suggest that SHS exposure may be a preventable factor for hypertension development in never smokers.

\section{Conflict of Interests}

There is no conflict of interests related to this paper.

\section{Authors' Contribution}

All the authors contributed to the intellectual development of this paper. O. Alshaarawy wrote the paper and was involved in statistical analysis. J. Xiao performed the statistical analyses and was involved in critical corrections of the paper. M. E. Andrew and C. Burchfiel provided statistical expertise and were involved in critical review and revision of the paper. A. Shanker had the original idea for the study, supervised the statistical analysis, and was involved in critical corrections of the paper.

\section{Acknowledgments}

This study was funded by an American Heart Association National Clinical Research Program grant and NIH/NIEHS Grants 1 R01 ES021825-01 and 5R03ES018888-02. The findings and conclusions in this paper are those of the authors and do not necessarily represent the views of the National Institute for Occupational Safety and Health.

\section{References}

[1] K. Nakamura, F. Barzi, T. H. Lam et al., "Cigarette smoking, systolic blood pressure, and cardiovascular diseases in the asiapacific region," Stroke, vol. 39, no. 6, pp. 1694-1702, 2008.

[2] B. Halvorsen, L. E. Sagen, T. Ueland, P. Aukrust, and S. Tonstad, "Effect of smoking cessation on markers of inflammation and endothelial cell activation among individuals with high risk for cardiovascular disease," Scandinavian Journal of Clinical and Laboratory Investigation, vol. 67, no. 6, pp. 604-611, 2007.

[3] T. Kondo, S. Osugi, K. Shimokata et al., "Smoking and smoking cessation in relation to all-cause mortality and cardiovascular events in 25,464 healthy male Japanese workers," Circulation Journal, vol. 75, no. 12, pp. 2885-2892, 2011.

[4] L. Landini and A. Leone, "Smoking and hypertension: effects on clinical, biochemical and pathological variables due to isolated or combined action on cardiovascular system," Current Pharmaceutical Design, vol. 17, no. 28, pp. 2987-3001, 2011.

[5] Centers for Disease Control and Prevention (CDC), "Vital signs: prevalence, treatment, and control of hypertensionUnited States, 1999-2002 and 2005-2008," Morbidity and Mortality Weekly Report, vol. 60, no. 4, pp. 103-108, 2011.

[6] M. Dochi, K. Sakata, M. Oishi, K. Tanaka, E. Kobayashi, and Y. Suwazono, "Smoking as an independent risk factor for 
hypertension: a 14-year longitudinal study in male Japanese workers," The Tohoku Journal of Experimental Medicine, vol. 217, no. 1, pp. 37-43, 2009.

[7] A. B. Thuy, L. Blizzard, M. D. Schmidt, P. H. Luc, R. H. Granger, and T. Dwyer, "The association between smoking and hypertension in a population-based sample of Vietnamese men," Journal of Hypertension, vol. 28, no. 2, pp. 245-250, 2010.

[8] T. K. Makris, C. Thomopoulos, D. P. Papadopoulos et al., "Association of passive smoking with masked hypertension in clinically normotensive nonsmokers," American Journal of Hypertension, vol. 22, no. 8, pp. 853-859, 2009.

[9] M. Yarlioglues, M. G. Kaya, I. Ardic et al., "Acute effects of passive smoking on blood pressure and heart rate in healthy females," Blood Pressure Monitoring, vol. 15, no. 5, pp. 251-256, 2010.

[10] A. Leone, "Interactive effect of combined exposure to active and passive smoking on cardiovascular system," Recent Patents on Cardiovascular Drug Discovery, vol. 6, no. 1, pp. 61-69, 2011.

[11] B. Q. Zhu and W. W. Parmley, "Hemodynamic and vascular effects of active and passive smoking," American Heart Journal, vol. 130, no. 6, pp. 1270-1275, 1995.

[12] R. S. Vasan, M. G. Larson, E. P. Leip, W. B. Kannel, and D. Levy, "Assessment of frequency of progression to hypertension in non-hypertensive participants in the Framingham Heart Study: a cohort study," The Lancet, vol. 358, no. 9294, pp. 1682-1686, 2001.

[13] V. Savica, G. Bellinghieri, and J. D. Kopple, "The effect of nutrition on blood pressure," Annual Review of Nutrition, vol. 30, pp. 365-401, 2010.

[14] S. D. Nesbitt, “Treatment options for prehypertension," Current Opinion in Nephrology and Hypertension, vol. 16, no. 3, pp. 250255, 2007.

[15] D. P. Papadopoulos, T. K. Makris, and V. Papademetriou, "Is it time to treat prehypertension?" Hypertension Research, vol. 31, no. 9, pp. 1681-1686, 2008.

[16] L. J. Appel, "ASH position paper: dietary approaches to lower blood pressure," Journal of the American Society of Hypertension, vol. 4, no. 2, pp. 79-89, 2010.

[17] L. J. Appel, "ASH position paper: dietary approaches to lower blood pressure," Journal of Clinical Hypertension, vol. 11, no. 7, pp. 358-368, 2009.

[18] L. J. Appel, M. W. Brands, S. R. Daniels, N. Karanja, P. J. Elmer, and F. M. Sacks, "Dietary approaches to prevent and treat hypertension: a scientific statement from the American Heart Association," Hypertension, vol. 47, no. 2, pp. 296-308, 2006.

[19] National Center for Health Statistics, "The National Health and Nutrition Examination Survey 2005-2006," Survey Operations Manuals, Brochures, Consent Documents, 2009, http://www.cdc.gov/nchs/nhanes/nhanes2005-2006/current nhanes_05_06.htm.

[20] National Center for Health Statistics, "The National Health and Nutrition Examination Survey 2007-2008," Survey Operations Manuals, Brochures, Consent Documents, 2009, http://www.cdc.gov/nchs/nhanes/nhanes2007-2008/current nhanes_07_08.htm.

[21] M. L. Cuddy, "Treatment of hypertension: guidelines from JNC 7 (the seventh report of the Joint National Committee on Prevention, Detection, Evaluation, and Treatment of High Blood Pressure 1)," The Journal of Practical Nursing, vol. 55, no. 4, pp. 17-21, 2005.

[22] A. V. Chobanian, G. L. Bakris, H. R. Black et al., "Seventh report of the Joint National Committee on Prevention, Detection,
Evaluation, and Treatment of High Blood Pressure," Hypertension, vol. 42, no. 6, pp. 1206-1252, 2003.

[23] National Center for Health Statistics, "Laboratory procedures used for NHANES, 2007-2008," 2009, http:/www.cdc.gov/ nchs/nhanes/nhanes2007-2008/lab07_08.htm.

[24] N. J. D. Nagelkerke, "A note on a general definition of the coefficient of determination," Biometrika, vol. 78, no. 3, pp. 691-692, 1991.

[25] L. Baer and I. Radichevich, "Cigarette smoking in hypertensive patients. Blood pressure and endocrine responses," American Journal of Medicine, vol. 78, no. 4, pp. 564-568, 1985.

[26] A. Groppelli, D. M. A. Giorgi, S. Omboni, G. Parati, and G. Mancia, "Persistent blood pressure increase induced by heavy smoking," Journal of Hypertension, vol. 10, no. 5, pp. 495-499, 1992.

[27] P. E. Cryer, M. W. Haymond, J. V. Santiago, and S. D. Shah, "Norepinephrine and epinephrine release and adrenergic mediation of smoking associated hemodynamic and metabolic events," The New England Journal of Medicine, vol. 295, no. 11, pp. 573-577, 1976.

[28] T. K. Makris, C. Thomopoulos, D. P. Papadopoulos et al., "Association of passive smoking with masked hypertension in clinically normotensive nonsmokers," American Journal of Hypertension, vol. 22, no. 8, pp. 853-859, 2009.

[29] N. L. Benowitz, F. Kuyt, and P. Jacob, "Cotinine disposition and effects," Clinical Pharmacology and Therapeutics, vol. 34, no. 5, pp. 604-611, 1983.

[30] S. C. Gorber, S. Schofield-Hurwitz, J. Hardt, G. Levasseur, and M. Tremblay, "The accuracy of self-reported smoking: a systematic review of the relationship between self-reported and cotinine-assessed smoking status," Nicotine \& Tobacco Research, vol. 11, no. 1, pp. 12-24, 2009.

[31] E. J. Perez-Stable, N. L. Benowitz, and G. Marin, "Is serum cotinine a better measure of cigarette smoking than self-report?" Preventive Medicine, vol. 24, no. 2, pp. 171-179, 1995.

[32] N. L. Benowitz, "Cotinine as a biomarker of environmental tobacco smoke exposure," Epidemiologic Reviews, vol. 18, no. 2, pp. 188-204, 1996.

[33] G. Grassi, G. Seravalle, D. A. Calhoun et al., "Mechanisms responsible for sympathetic activation by cigarette smoking in humans," Circulation, vol. 90, no. 1, pp. 248-253, 1994.

[34] A. Leone, "Does smoking act as a friend or enemy of blood pressure? Let release Pandora's box," Cardiology Research and Practice, vol. 2011, Article ID 264894, 7 pages, 2011.

[35] D. S. Celermajer, K. E. Sorensen, D. Georgakopoulos et al., "Cigarette smoking is associated with dose-related and potentially reversible impairment of endothelium-dependent dilation in healthy young adults," Circulation, vol. 88, no. 5, pp. 21492155, 1993.

[36] R. S. Barua, J. A. Ambrose, L. J. Eales-Reynolds, M. C. DeVoe, J. G. Zervas, and D. C. Saha, "Dysfunctional endothelial nitric oxide biosynthesis in healthy smokers with impaired endothelium-dependent vasodilatation," Circulation, vol. 104, no. 16, pp. 1905-1910, 2001.

[37] K. Kugiyama, H. Yasue, M. Ohgushi et al., "Deficiency in nitric oxide bioactivity in epicardial coronary arteries of cigarette smokers," Journal of the American College of Cardiology, vol. 28, no. 5, pp. 1161-1167, 1996.

[38] R. G. Ijzerman, E. H. Serne, M. H. Van Weissenbruch, R. T. De Jongh, and C. D. A. Stehouwer, "Cigarette smoking is associated with an acute impairment of microvascular function in humans," Clinical Science, vol. 104, no. 3, pp. 247-252, 2003. 
[39] J. Hukkanen, P. Jacob, and N. L. Benowitz, "Metabolism and disposition kinetics of nicotine," Pharmacological Reviews, vol. 57, no. 1, pp. 79-115, 2005.

[40] S. Mollerup, D. Ryberg, A. Hewer, D. H. Phillips, and A. Haugen, "Sex differences in lung CYP1A1 expression and DNA adduct levels among lung cancer patients," Cancer Research, vol. 59, no. 14, pp. 3317-3320, 1999.

[41] W. Han, B. T. Pentecost, R. L. Pietropaolo, M. J. Fasco, and S. D. Spivack, "Estrogen receptor $\alpha$ increases basal and cigarette smoke extract-induced expression of CYP1A1 and CYP1B1, but not GSTP1, in normal human bronchial epithelial cells," Molecular Carcinogenesis, vol. 44, no. 3, pp. 202-211, 2005.

[42] W. Q. Gan, S. B. Z. Cohen, S. F. Paul Man, and D. D. Sin, "Sexrelated differences in serum cotinine concentrations in daily cigarette smokers," Nicotine \& Tobacco Research, vol. 10, no. 8, pp. 1293-1300, 2008.

[43] P. Primatesta, E. Falaschetti, S. Gupta, M. G. Marmot, and N. R. Poulter, "Association between smoking and blood pressure evidence from the health survey for England," Hypertension, vol. 37, no. 2, pp. 187-193, 2001.

[44] S. Lemieux, D. Prud'homme, C. Bouchard, A. Tremblay, and J. P. Despres, "Sex differences in the relation of visceral adipose tissue accumulation to total body fatness," American Journal of Clinical Nutrition, vol. 58, no. 4, pp. 463-467, 1993.

[45] J. Vague, "The degree of masculine differentiation of obesities: a factor determining predisposition to diabetes, atherosclerosis, gout, and uric calculous disease," The American Journal of Clinical Nutrition, vol. 4, no. 1, pp. 20-34, 1956.

[46] H. Kvist, B. Chowdhury, U. Grangard, U. Tylen, and L. Sjostrom, "Total and visceral adipose-tissue volumes derived from measurements with computed tomography in adult men and women: predictive equations," American Journal of Clinical Nutrition, vol. 48, no. 6, pp. 1351-1361, 1988.

[47] L. Sjöström and H. Kvist, "Regional body fat measurements with CT-scan and evaluation of anthropometric predictions," Acta Medica Scandinavica, vol. 222, no. S723, pp. 169-177, 1987.

[48] R. B. Jain and J. T. Bernert, "Effect of body mass index and total blood volume on serum cotinine levels among cigarette smokers: NHANES 1999-2008," Clinica Chimica Acta, vol. 411, no. 15-16, pp. 1063-1068, 2010.

[49] R. S. Caraballo, G. A. Giovino, T. F. Pechacek et al., "Racial and ethnic differences in serum cotinine levels of cigarette smokers: third National Health and Nutrition Examination Survey, 19881991," Journal of the American Medical Association, vol. 280, no. 2, pp. 135-139, 1998.

[50] L. E. Wagenknecht, G. R. Cutter, N. J. Haley et al., "Racial differences in serum cotinine levels among smokers in the Coronary Artery Risk Development in (Young) Adults Study," American Journal of Public Health, vol. 80, no. 9, pp. 1053-1056, 1990.

[51] W. Kalow, "Ethnic differences in reactions to drugs and xenobiotics. Caffeine and other drugs," Progress in Clinical and Biological Research, vol. 214, pp. 331-341, 1986.

[52] M. Rahman, J. R. Temple, C. R. Breitkopf, and A. B. Berenson, "Racial differences in body fat distribution among reproductive-aged women," Metabolism: Clinical and Experimental, vol. 58, no. 9, pp. 1329-1337, 2009. 


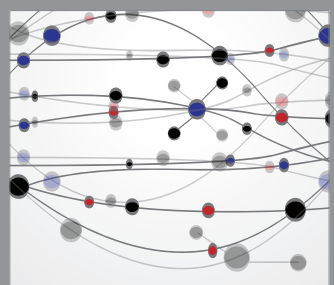

The Scientific World Journal
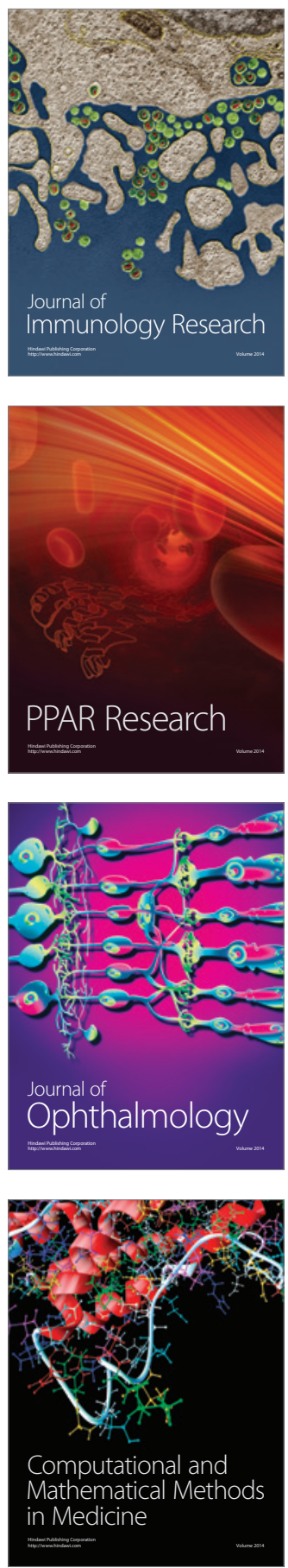

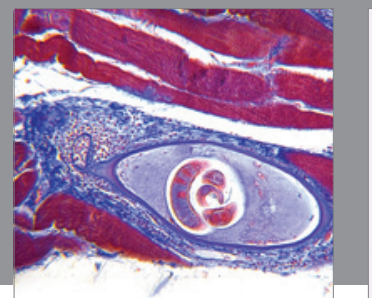

Gastroenterology

Research and Practice
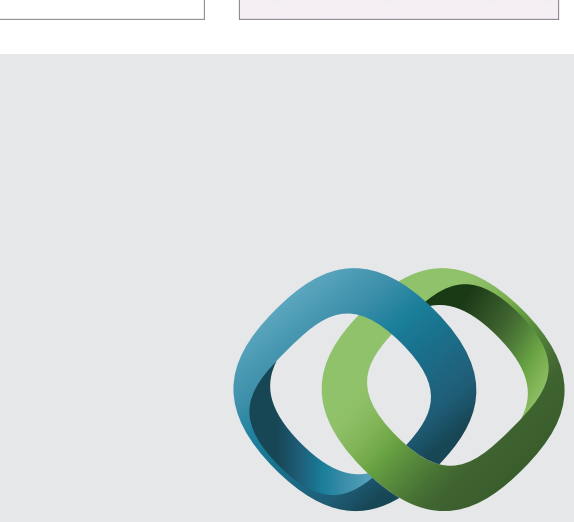

\section{Hindawi}

Submit your manuscripts at

http://www.hindawi.com
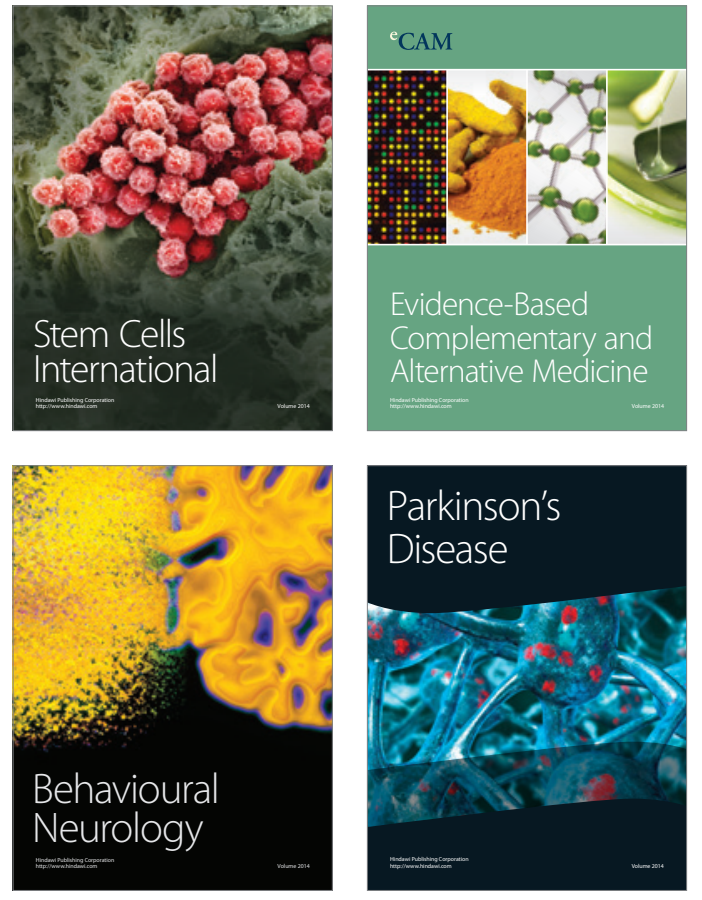
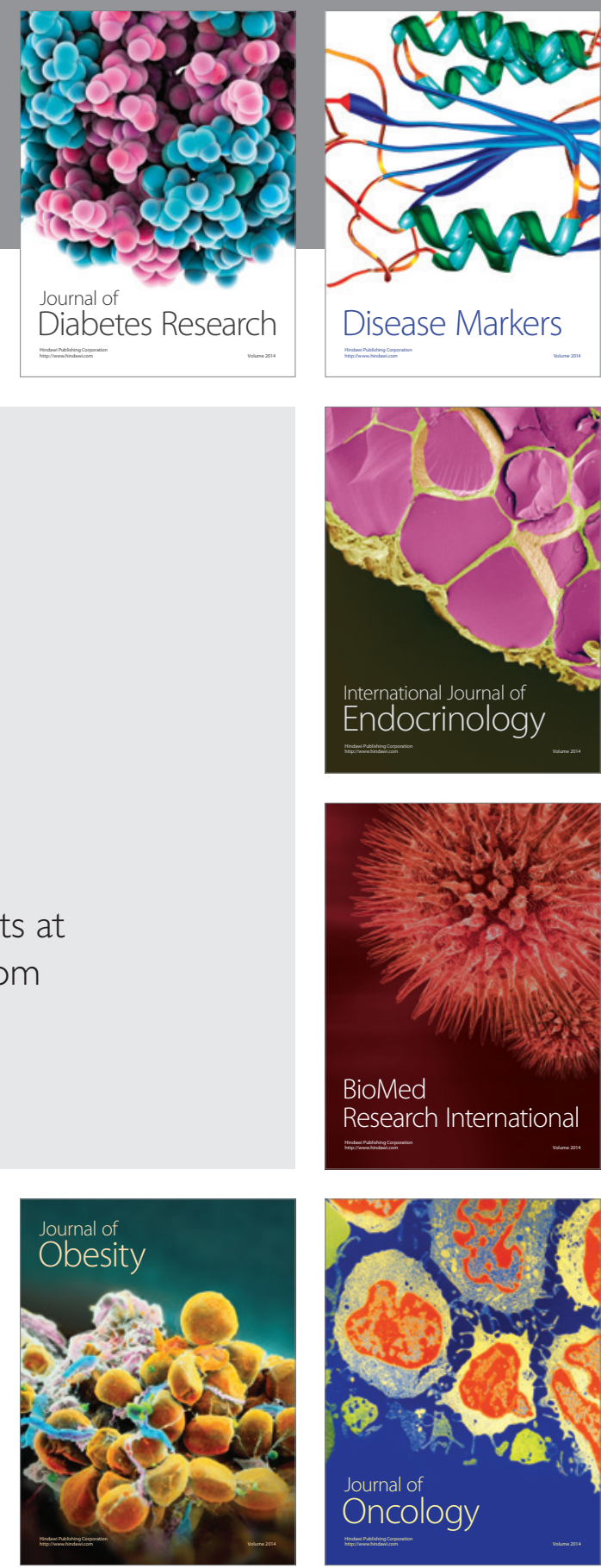

Disease Markers
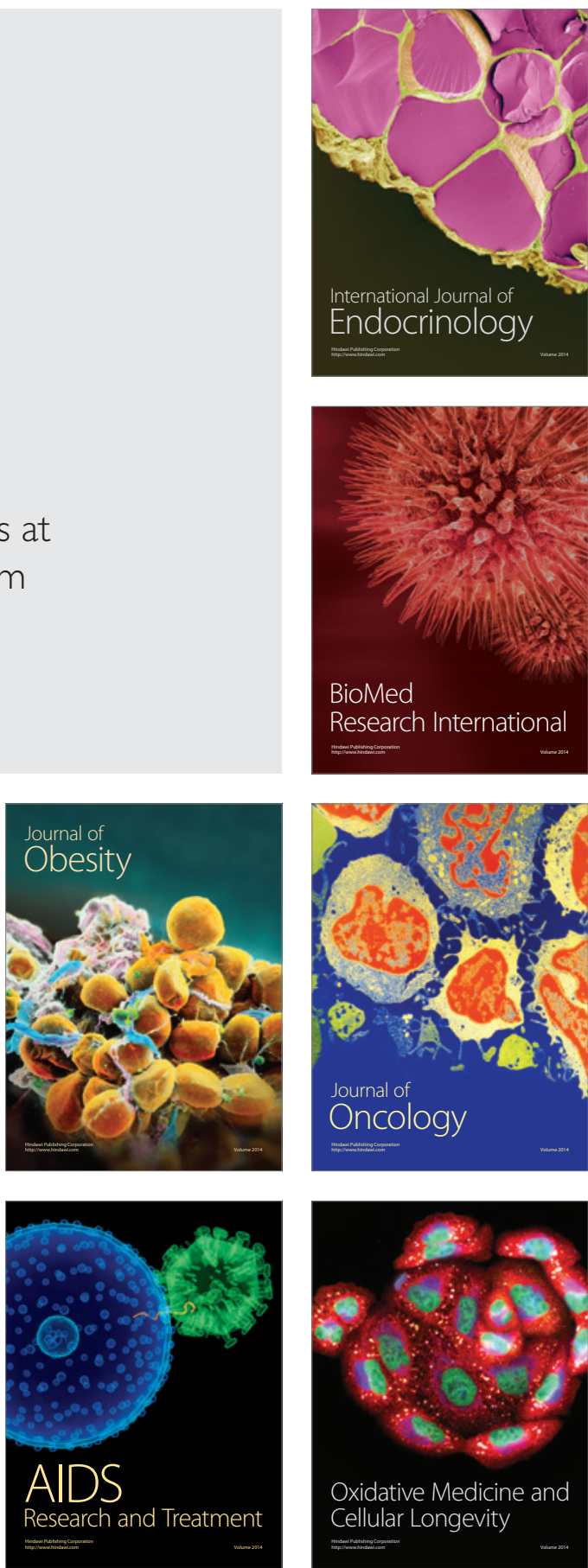